\title{
DETEKSI DINI TUMBUH KEMBANG ANAK PRASEKOLAH DI TK NIDZAMIYAH KECAMATAN MOJOROTO KOTA KEDIRI TAHUN 2017
}

\author{
Siswi Wulandari ${ }^{1}$, Dewi Kartika Sari ${ }^{2}$,Dewi Nur Afifi ${ }^{3}$ \\ ${ }^{1}$ Fakultas Ilmu Kesehatan Universitas Kadiri \\ SiswiWulandari@unik-kediri.ac.id \\ 2 Fakultas Ilmu Kesehatan Universitas Kadiri \\ dewikartika@unik-kediri.ac.id \\ ${ }^{3}$ Fakultas Ilmu Kesehatan Universitas Kadiri \\ afifidewi@unik-kediri.ac.id
}

\section{A. ABSTRAK}

Anak merupakan aset penerus bangsa yang harus dijaga dan dirawat agar bisa menjadi SDM yang berkualitas. Agar menjadi SDM yang berkualitas maka diperlukan gizi serta pola asuh yang baik untuk menujang pertumbuhan dan perkembanganya. Pertumbuhan dan perkembangan merupakan tahapan penting yang harus dipantau agar pertumbuhan dan perkembangan berjalan sesuai dengan usianya,

Anak di Indonesia perlu mendapat perhatian serius terutama anak prasekolah yaitu untuk mendapat gizi yang baik, stimulasi yang memadai serta terjangkau oleh pelayanan kesehatan berkualitas termasuk deteksi dan intervensi dini penyimpangan tumbuh kembang sehingga dapat tumbuh dan berkembang secara optimal sesuai dengan potensi genetiknya dan mampu bersaing di era global.

Permasalahan yang ditemukan di TK Nidzamiyah adalah masih belum pernah dilakukan deteksi dini tumbuh kembang pada anak prasekolah. Tujuan dari di pelaksanaan kegiatan ini adalah untuk melakukan deteksi dini tumbuh yang diharapkan apabila terjadi penyimpangan tumbuh kembang bisa terdeteksi secara dini serta diharapkan tumbuh kembang bisa berjalan dengan normal sesuai dengan usia. 
Target khusus dari kegiatan ini secara langsung berdampak pada pengembangan dan pengaplikasian ilmu, teknologi di perguruan tinggi. Metode yang akan dilaksanakan pada kegiatan ini adalah identifikasi tumbuh kembang anak prasekolah di TK Nidzamiyah Kota Kediri.

Kata Kunci : anak prasekolah, tumbuh kembang, deteksi dini

\section{B. PENDAhuluan}

Pembangunan kesehatan merupakan bagian dari upaya membangun manusia seutuhnya yang diselenggarakan melalui upaya kesehatan anak sedini mungkin sejak anak masih dalam kandungan. Upaya kesehatan yang dilakukan sejak anak masih di dalam kandungan sampai lima tahun pertama kehidupannya, bertujuan untuk mempertahankan kelangsungan hidupnya serta meningkatkan kualitas hidup anak agar mencapai tumbuh kembang optimal baik fisik, mental, emosional dan sosial serta memiliki intelegensi majemuk sesuai dengan potensi genetiknya. ${ }^{1 .}$ Pertumbuhan dan perkembangan anak secara fisik, mental, sosial, emosional dipengaruhi oleh gizi, kesehatan dan pendidikan. Penelitian longitudinal yang dilakukan oleh Bloom mengenai kecerdasan menunjukkan bahwa perkembangan kognitifnya mencapai sekitar 50\% dalam kurun waktu empat tahun pertama usia anak, mencapai $80 \%$ dalam kurun waktu 8 tahun, dan mencapai $100 \%$ setelah anak berusia 18 tahun. ${ }^{2}$

Jumlah populasi anak prasekolah di Indonesia adalah sekitar 10\% dari seluruh populasi, kualitas tumbuh kembang anak Prasekolah di Indonesia perlu mendapat perhatian serius karena merekalah calon generasi penerus bangsa, untuk itu anak perlu mendapat gizi yang baik, stimulasi yang memadai serta terjangkau oleh pelayanan kesehatan berkualitas termasuk deteksi dan intervensi dini penyimpangan tumbuh kembang, sehingga dapat tumbuh dan berkembang secara optimal sesuai dengan potensi genetiknya dan mampu bersaing di era global. ${ }^{1}$

Pembinaan tumbuh kembang anak secara komprehensif dan berkualitas tersebut dapat diselenggarakan melalui kegiatan stimulasi, deteksi dan intervensi dini penyimpangan tumbuh kembang anak prasekolah. Program Stimulasi, Deteksi dan Intervensi Dini Tumbuh Kembang (SDIDTK) merupakan revisi dari program Deteksi 
Dini Tumbuh Kembang (DDTK) yang telah dilakukan sejak tahun 1988 dan termasuk salah satu program pokok Puskesmas. Kegiatan ini dilakukan menyeluruh dan terkoordinasi diselenggarakan dalam bentuk kemitraan antara keluarga (orang tua, pengasuh anak dan anggota keluarga lainnya), masyarakat (kader, organisasi profesi, lembaga swadaya masyarakat) dengan tenaga professional. ${ }^{1}$ Pemerintah telah melakukan beberapa upaya dalam mendukung pelaksanaan SDIDTK. Salah satu program pemerintah untuk menunjang upaya tersebut adalah diterbitkannya buku Pedoman Pelaksanaan Stimulasi, Deteksi dan Intervensi Dini Tumbuh Kembang di Tingkat Pelayanan Kesehatan Dasar. Upaya lain yang dilakukan adalah pelatihan SDIDTK bagi tenaga kesehatan baik di kabupaten, kota maupun di Puskesmas. ${ }^{2}$

Melalui kegiatan SDIDTK kondisi terparah dari penyimpangan pertumbuhan anak seperti gizi buruk dapat dicegah, karena sebelum anak jatuh dalam kondisi gizi buruk, penyimpangan pertumbuhan yang terjadi pada anak dapat terdeteksi melalui kegiatan SDIDTK. Selain mencegah terjadinya penyimpangan pertumbuhan, kegiatan SDIDTK juga mencegah terjadinya penyimpangan perkembangan dan penyimpangan mental emosional. ${ }^{1}$

SDIDTK sangat diperlukan untuk menemukan secara dini penyimpangan pertumbuhan, penyimpangan perkembangan dan penyimpangan mental emosional pada anak sehingga dapat dilakukan intervensi dan stimulasi sedini mungkin untuk mencegah terjadinya penyimpangan pertumbuhan, penyimpangan perkembangan dan penyimpangan mental emosional yang menetap. Kegiatan SDIDTK tidak hanya dilakukan pada anak yang dicurigai mempunyai masalah saja tetapi harus dilakukan pada semua Prasekolah dan anak pra sekolah secara rutin setahun 2 kali. ${ }^{1}$ Maka dari dalam program pengabdian masyarakat ini dilakukan deteksi dini tumbuh kembang anak prasekolah di TK Nidzamiyah Kota Kediri. 


\section{METODE PELAKSANAAN}

Dalam rangka untuk mengatasi permasalahan yang dihadapi mitra, yaitu belumpernah dilakukan deteksi dini anak prasekolah di TK Nidzamiyah adalah sebagai berikut:

1. Melakukan deteksi dini tumbuh kembang anak prasekolah di TK Nidzamiyah Kota Kediri dengan menggunakan lembar KPSP, adapun prosedur pelaksanaan pengabdian masyarakat sebagai berikut:

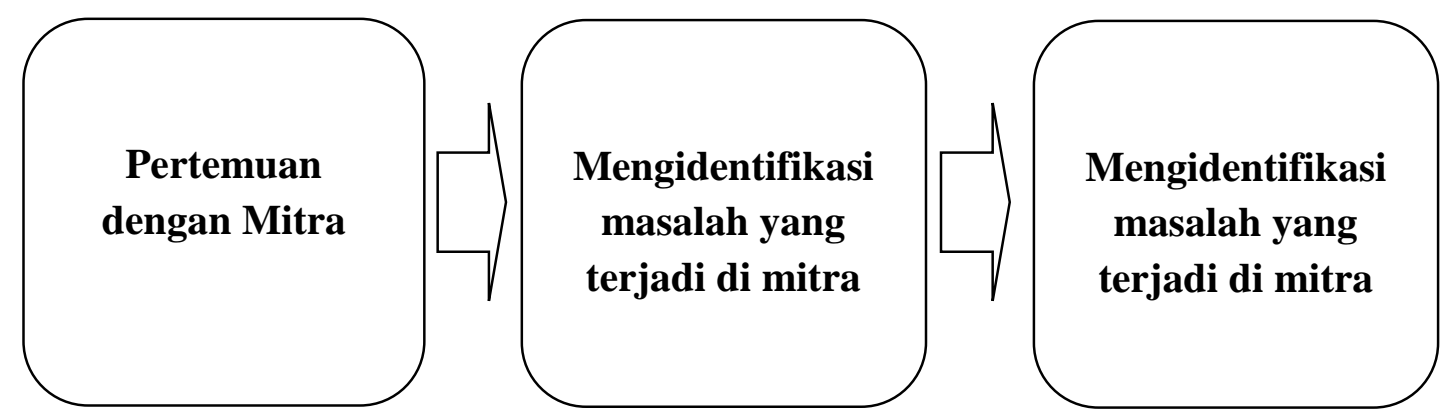

Adapun pelaksanaan kegiatan ini diuraikan dalam tabel berikut:

\begin{tabular}{lll}
\hline NO & KEGIATAN & \multicolumn{1}{c}{ URAIAN KEGIATAN } \\
\hline 1 & Persiapan & Observasi ulang lokasi setelah proposal lulus seleksi \\
\cline { 2 - 3 } & Koordinasi ulang dengan kepala TK \\
\cline { 2 - 3 } & Penyusunan Kegiatan, dengan rincian sebagai berikut : \\
& - Peserta yang hadir di lakukan pendataan tentang nama \\
& dan usianya dengan menanyakannya pada orang tua \\
& yang mendampingi. \\
& - Dilakukan pemeriksaan BB dan TB \\
& - Dilakukan tes perkembangan dengan menggunakan \\
& KPSP \\
& - Kesimpulan dari hasil pemeriksaan disampaikan ke \\
& orang tua untuk dijadikan masukan \\
& - Kumpulan hasil pemeriksaan direkap dan disampaikan \\
& ke pihak mitra. \\
\cline { 2 - 3 } & Persiapan bahan dan alat yang terdiri dari : \\
& - Timbangan Berat bandan \\
& - Alat pengukur tinggi badan \\
& - Lembar KPSP \\
& -3 set alat permainan sesuai dengan perkembangan \\
& anak usia 2-6 tahun \\
& - Alat tulis dan kertas \\
\hline & Deteksi Dini Tumbuh Kembang Anak Prasekolah \\
& dibantu oleh mahasiswa \\
&
\end{tabular}




\section{Hasil dan Pembahasan}

- Judul Kegiatan

"Deteksi Dini Tumbuh Kembang Anak Prasekolah Di Tk Nidzamiyah Kecamatan Mojoroto Kota Kediri”

- Waktu, Tempat Pelaksanaan, Peserta Pelaksanaan kegiatan Deteksi Dini Tumbuh Kembang pada Tanggal 02 Desember 2017 di TK Nidzamiyah Kota Kediri. Peserta dalam kegiatan ini adalah seluruh anak prasekolah di TK Nidzamiyah Kota Kediri.

- Sasaran/Target Kegiatan

Sasaran seluruh anak prasekolah di TK Nidzamiyah Kota Kediri hadir dalam kegiatan lomba kolase di TK Nidzamiyah Kota Kediri sebanyak 43 anak.

\section{- Pelaksanaan Kegiatan Deteksi Dini Tumbuh Kembang}

Lembaga Penelitian dan Pengabdian kepada Masyarakat (LPPM) Fakultas Ilmu Kesehatan Universitas Kadiri dalam melaksanakan semua gerak dan langkah didukung oleh berbagai sumber daya dari berbagai jurusan sesuai dengan program yang ditawarkan. Kegiatan deteksi dini tumbuh kembuh kembang ini dilaksanakan oleh tim dosen dari program studi Kebidanan DIV Fakultas Ilmu Kesehatan Universitas Kadiri yang dibantu oleh 10 orang mahasiswa. Deteksi dini dalam kegiatan Pengabdian Masyarakat ini mencapai keberhasilan karena dukungan berbagai pihak yang terkait dan mau bekerjasama dengan baik, yaitu pihak mitra (TK Nidzamiyah). Hasil dari kegiatan deteksi dini tumbuh kembang yang dilakukan, dapat dijadikan masukan dan bahan evaluasi untuk ditindaklanjuti oleh pihak mitra. Untuk lebih jelasnya terhadap rangkaian kegiatan yang dilakukan, dapat dilihat dari adanya beberapa dokumentasi pada lampiran.

\section{- Hasil Deteksi Dini Tumbuh Kembang}

Peserta dalam kegiatan ini adalah anak prasekolah yang terdaftar di TK Nidzamiyah sebanyak. setelah dilakukan penyuluhan dan pemeriksaan tumbuh kembang anak dengan menggunakan KPSP dan diulakukan pengukuran berat badan, tinggi badan. Dan hasil terlampir dalam tabel berikut. 
Tabel 1. Hasil Pengukuran Berat Badan/Umur

\begin{tabular}{cccc}
\hline No & Klasifikasi & Frekuensi & Prosentase \\
\hline 1 & Gizi Buruk & 0 & $0 \%$ \\
\hline 2 & Gizi Kurang & 3 & $7 \%$ \\
\hline 3 & Gizi Baik & 35 & $81,4 \%$ \\
\hline 4 & Gizi Lebih & 5 & $11,6 \%$ \\
\hline & Jumlah & $\mathbf{4 3}$ & $\mathbf{1 0 0} \%$ \\
\hline
\end{tabular}

Dari hasil tabel diatas didapatkan $81,4 \%$ anak prasekolah yang gizi baik

Tabel 2. Hasil Pengukuran Tinggi Badan/Umur

\begin{tabular}{cccc}
\hline No & Klasifikasi & Frekuensi & Prosentase \\
\hline 1 & Sangat Pendek & 0 & $0 \%$ \\
\hline 2 & Pendek & 4 & $9,3 \%$ \\
\hline 3 & Normal & 39 & $90,7 \%$ \\
\hline & Jumlah & $\mathbf{4 3}$ & $\mathbf{1 0 0} \%$ \\
\hline
\end{tabular}

Dari hasill tabel diatas didapatkan $90,7 \%$ anak prasekolah yang tinggi badanya normal

Tabel 3. Hasil Tes Perkembangan dengan KPSP

\begin{tabular}{lccc}
\hline No & Klasifikasi & Frekuensi & Prosentase \\
\hline 1 & Sesuai & 40 & $93 \%$ \\
\hline 2 & Meragukan & 3 & $7 \%$ \\
\hline 3 & Penyimpangan & 0 & $0 \%$ \\
\hline & Jumlah & $\mathbf{4 3}$ & $\mathbf{1 0 0} \%$ \\
\hline
\end{tabular}

Dari hasil tabel diatas didapatkan $93 \%$ anak prasekolah perkembanya sesuai.

\section{- Pembahasan}

Pertumbuhan erat kaitannya dengan masalah perubahan, baik itu jumlah, ukuran ataupun dimensi. Deteksi dini pertumbuhan pada anak bertujuan untuk mengetahui dan menemukan status gizi dari anak tersebut. Berdasarkan hasil pengukuran yang tabel 1, didapatkan hasil yang menyatakan bahwa $81,4 \%$ anak prasekolah yang gizi baik dan tidak ada yang mengalami pertumbuhan yang buruk, hanya saja ada 3 anak yang memiliki berat badan yang masih kurang. Berdasarkan wawancara dengan orang tua anak, diketahui bahwa anaknya memiliki nafsu makan yang kurang. Kurangnya nafsu makan anak bisa dipengaruhi oleh banyak hal, salah satunya adalah kurangnya variasi dalam memberikan menu makanan, sehingga muncul kebosanan pada anak. Orang tua responden mengaku memang dalam memberikan menu makanan terlalu monoton, 
dengan alasan kemampuan ekonomi yang tidak memadai untuk menyajikan menu yang bervariasi. Dengan adanya permasalahan tersebut, pemeriksa menegaskan pada orang tua anak, bahwa untuk menyajikan menu yang bervariasi tidak harus mahal, banyak bahan yang murah dan mudah didapatkan untuk menciptakan menu yang diminati anak. Kebutuhan zat gizi anak harus dapat dipenuhi, karena dengan adanya asupan gizi yang cukup anak akan tumbuh dengan baik, pertumbuhan yang baik nantinya juga akan mendukung perkembangan anak lebih baik. Pertumbuhan dan perkembangan harus berjalan beriringan dan saling mendukung, sebab keduanya sama-sama dibutuhkan untuk kelangsungan hidup anak.

Berdasarkan hasil wawancara dengan guru ataupun orang tua murid, deteksi dini terhadap perkembangan memang belum pernah dilakukan sebelumnya, banyaknya orang tua peserta yang berpartisipasi dalam kegiatan ini menjadi bukti bahwa sebenarnya orang tua sebenarnya memiliki kepedulian yang tinggi terhadap tumbuh kembang anak, namun karena kurang adanya kesempatan dan sarana sehingga anak tidak pernah melakukan tes perkembangan. Dari hasil deteksi dini menunjukan terhadap perkembangan anak prasekolah di TK nidzamiyah didapatkan hasil yang menyatakan bahwa 93\% anak prasekolah perkembanya sesuai berjalan sesuai dengan tahapan usia, adapun $7 \%$ yang lain masih meragukan, hal ini dimungkinkan anak sudah merasa lelah atau bosan saat dilakukan pemeriksaan, untuk itu anak tersebut perlu dilakukan pemeriksaan ulang di lain waktu untuk memastikan hasil perkembangan yang didapatkan. Deteksi terhadap tumbuh kembang anak harus tetap dilakukan minimal 6 bulan sekali untuk tetap mendeteksi apabila terjadi penyimpangan dalam proses tumbuh kembangnya untuk mewujudkan tujuan bersama yaitu mencetak generasi yang sehat dan cerdas. 


\section{E. Daftar Pustaka}

Depkes RI. 2007. Pedoman Pelaksanaan Stimuasi, Deteksi dan Intervensi Dini Tumbuh Kembang Anak di Tingkat Pelayanan Kesehatan Dasar. Jakarta : Depkes RI

Irmawati. 2007. Analisis Hubungan Fungsi Manajemen Pelaksana Kegiatan Stimulasi Deteksi dan Intervensi Dini Tumbuh Kembang (SDIDTK) dengan Cakupan SDIDTK Balita dan Anak Pra Sekolah di Puskesmas Kota Semarang Tahun 2007 (Tesis). Semarang : Undip Semarang

Saidah, E.S. 2003. Pentingnya Stimulasi Mental Dini. Jurnal Ilmiah Pendidikan Anak Usia Dini. No.01.hlm. 50-55. 


\section{LAMPIRAN}

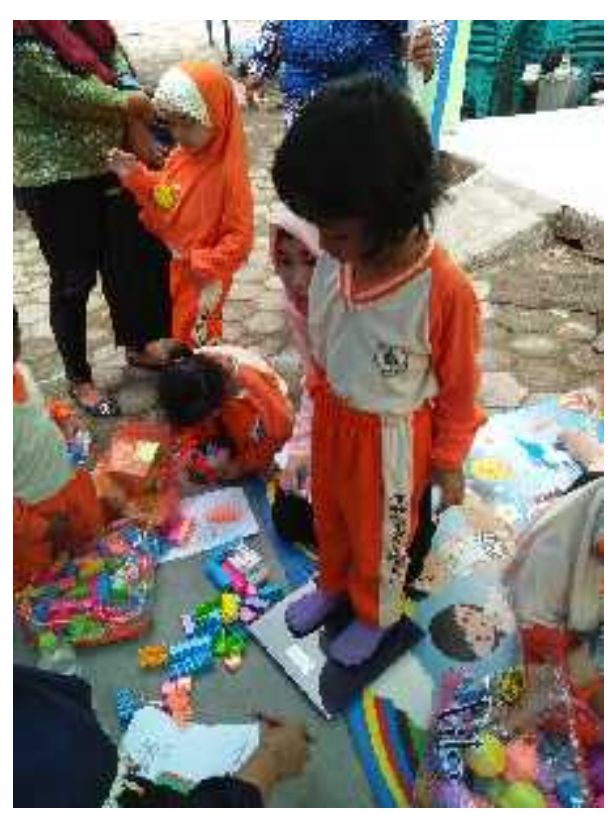

Pemeriksaan berat badan anak
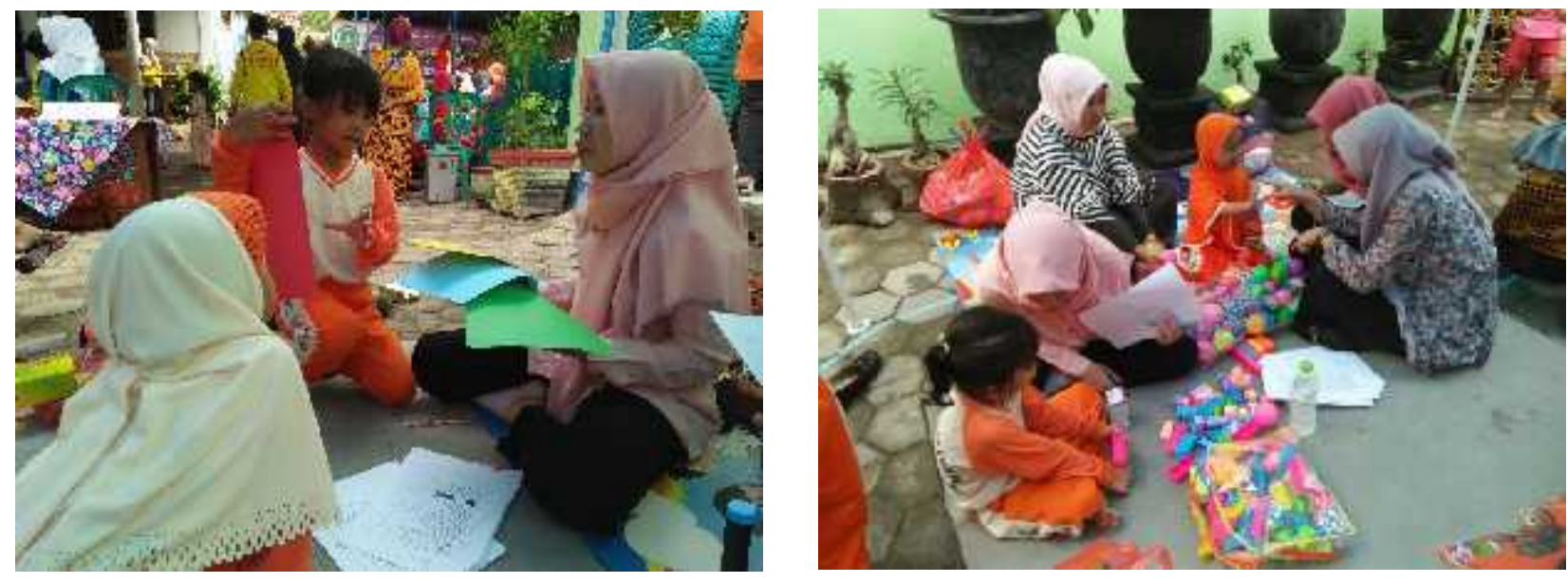

Pemeriksaan perkembangan anak dengan menggunakan KPSP 

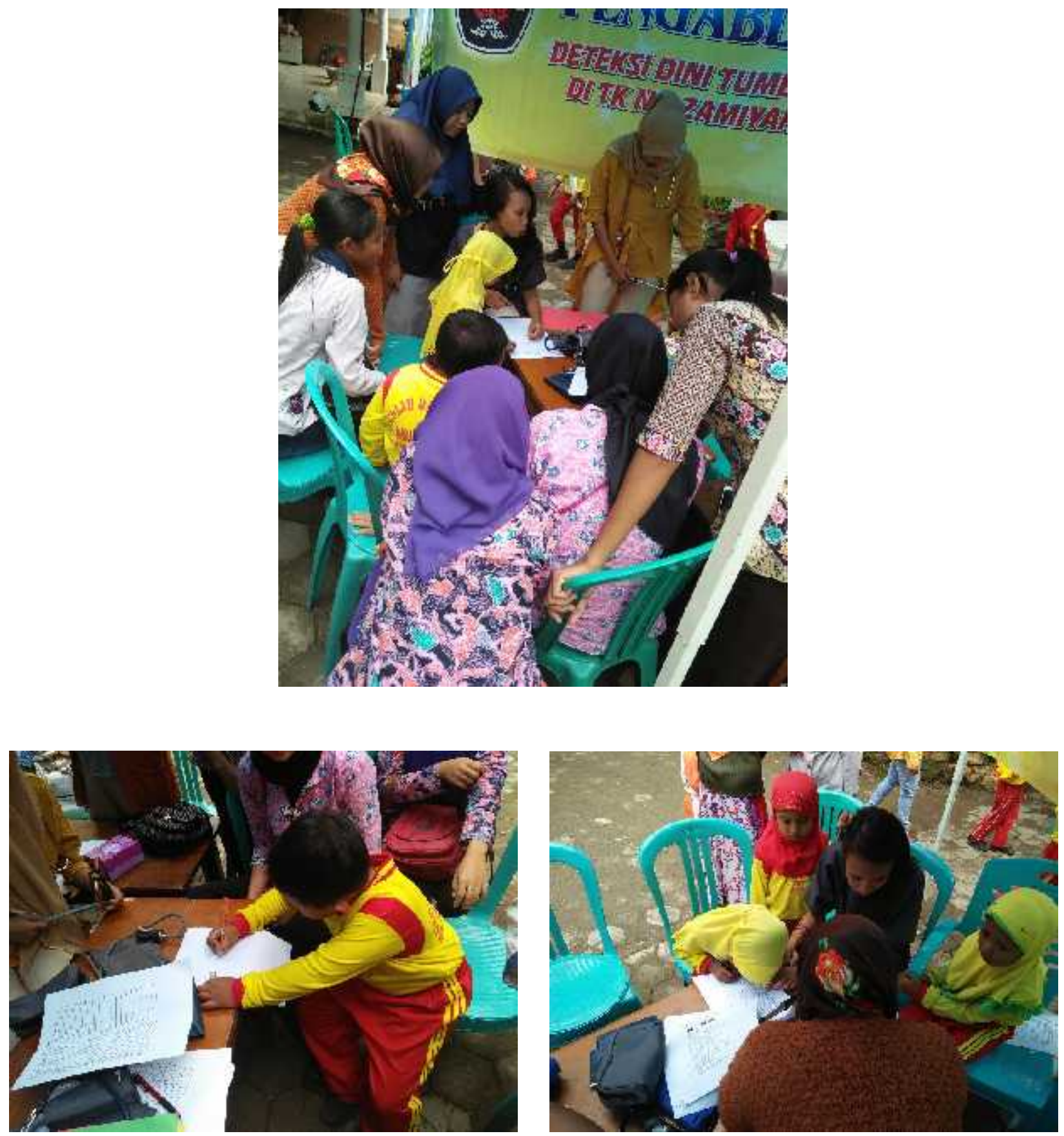

Murid TK Nidzamiyah sedang menjalani tes perkembangan 

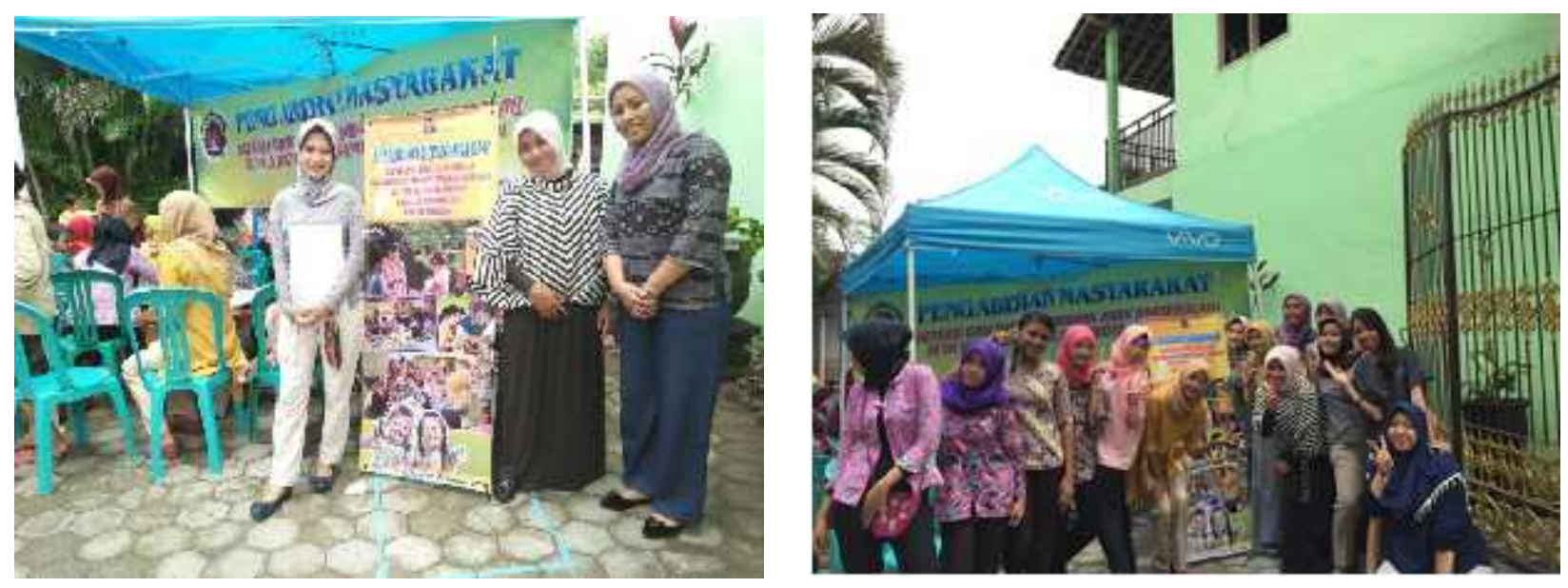

Dokumentasi Dosen dan Mahasiwi yang menjalankan kegiatan pengabmas 